\title{
Sustaining Sustainability in Organizations
}

\author{
Deborah E. de Lange $\cdot$ Timo Busch • \\ Javier Delgado-Ceballos
}

Published online: 15 August 2012

(C) Springer Science+Business Media B.V. 2012

The importance of social issues and the natural environment to societies and firms has dramatically evolved in the preceding 50 years. Corporate managers are becoming aware of the need to broaden their goals, beyond the traditional financial expectations. Since the term sustainability has entered the business world, an ever increasing number of firms realize the importance of sustainability and emphasize the social and environmental goals of their organizations (Bansal 2005; Hoffman 1999; GRI 2011). How seriously are these goals considered in corporate strategy? Is sustainability a trendy buzzword without any substantial meaning for operational processes? Or, can we observe tangible improvements in corporate social and environmental performance over time? These and related questions lead to an overarching question: How can sustainability be sustained in organizations?

Sustainability can be defined, based on earlier definitions, as an approach to business that considers economic, environmental and social issues in balanced, holistic, and long-term ways that benefit current and future generations of concerned stakeholders (Elkington 1998; World Commission on Environment and Development 1987). In other words, organizations aiming to be sustainable are required to pay attention to their performance on three dimensions:

D. E. de Lange $(\square)$

Memorial University of Newfoundland, St. John's, NL A1B

3X5, Canada

e-mail: ddelange@mun.ca

T. Busch

ETH Zurich, Weinbergstraße 56, Room WEV J 422, 8032

Zurich, Switzerland

J. Delgado-Ceballos

School of Economics and Business, University of Granada,

Campus Cartuja s/n, 18071 Granada, Spain economic performance, social equity, and ecological preservation (Gladwin et al. 1995).

A large established literature has been growing in the area of sustainability in organizations, particularly business firms. Some main goals in the sustainability research are to better understand why and how firms decide to adopt more sustainable practices. Considering this literature, two important research streams are noticeable: Researchers have examined both the external drivers, for example, pressures from stakeholders (e.g., Kassinis and Vafeas 2006), and the internal drivers (e.g., Aragón-Correa and Sharma 2003) that motivate organizations to implement a sustainability agenda. However, little attention has been paid to how sustainable practices remain in place and continue to develop over time. This special issue of the Journal of Business Ethics, Sustaining Sustainability in Organizations, intends to address this gap by advancing research that relates to how sustainability is developed and maintained (sustained) in organizations through the lens of strategy and organizations theory. The theoretical and empirical research in this issue-four papers are empirical and two are conceptual-contributes on multiple levels and examines the sustainability concerns of management and ethicists. The impact of ethical, sustainable thinking and the associated deep rooted changes have impacted the business world. Now, managers and others must insure that the sense of urgency and actions are sustained so that ground is not lost and rather, see that ethical, sustainable progress continues. The research in this issue develops the area of sustainability so that it moves to a higher level and matures. Otherwise, an obvious risk is that firm sustainability becomes only a convenient facade having little substantial meaning.

Corporate ethics and social responsibility are intertwined in this ongoing attempt to sustain sustainability in 
organizations. Literature has been building on this topic from many different perspectives. This special issue emphasizes three main topics. First, firms' sustainability performance and improvements to it may be encouraged through reporting and monitoring. In the monitoring literature, an important issue has been whether voluntary or regulatory approaches are more effective in changing firms' behavior to be sustainable and improve accordingly (Hess 2008; Chatterji and Listokin 2007). A key concern has been whether firms' reporting practices reflect substantive or symbolic behavior, the latter often referred to as "greenwashing" (Delmas and Cuerel Burbano 2011). Two empirical papers in this issue, both at the firm level of analysis, examine firms' self-monitoring and assurance practices. One paper considers different stakeholder groups' influence on a firm's strategic decisions related to CSR and the other focuses on large multinationals and the evolution of third-party assurance of sustainability reports.

Second, another main topic of this issue is identifying antecedents of sustainability adoption (Husted and Allen 2007). For example, what are the important attributes of firms, their contexts, and management that tend to facilitate the corporate adoption of sustainability? In this special issue, the focus is on what these attributes are for sustaining sustainability in firms rather than examining factors affecting or facilitating initial adoption. Two empirical papers in this issue take a firm-internal perspective as a theoretical lens, one using the resource-based view (RBV) of the firm and the other, the concept of dynamic capabilities (Barney 1991; Hart 1995; Luo 2000; Teece et al. 1997). Whereas the RBV paper examines interorganizational alliances, and considers partner heterogeneity of different types of organizations, the dynamic capabilities paper examines the joint effect of intraorganizational activities on sustainable firm behavior. Both sets of research are in agreement that a firm's innovativeness is important for facilitating sustainability. Also, the two theoretical papers of this issue contribute along this vein of considering attributes. One examines managers' attitudes and legitimation of sustainability at the individual level, whereas the other considers national culture's effect on firm context that affects a firm's sustainable behavior. Thus, one paper is bottom-up, examining how individuals affect sustainable firm behavior, whereas the other is more top-down, examining how the national context affects sustainable firm behavior. Both papers offer two very interesting and complementary perspectives.

The third main topic of this issue is the international aspect of sustainability. In exploring the various approaches that organizations have taken to maintain sustainability and spread good practices in an international context, we gain a better understanding of problems faced by different types of organizations such as multinational corporations (MNCs), non-governmental organizations (NGOs), and international governmental organizations (IGOs). An international level of focus is incorporated so as to consider the important challenge that globalizing organizations face as they spread sustainability practices to subsidiaries and consider partner organizations' practices. The challenge is formidable on an international scale, if not difficult enough at a local or national level. This special issue aims to be of interest to those scholars who study the challenges that the globally interweaved world faces in respect of improving firms' sustainable behavior. This holds importance in light of the recent Rio+20 United Nations conference that saw a lower level of international enthusiasm for its aims than in previous decades.

In this globalized context, NGOs and their vested interests in influencing firms to become more sustainable are of increasing importance. They are involved in setting up different approaches such as creating voluntary reporting systems and partnering with firms. However, it is important to mirror how genuinely firms are involved in voluntary activities. Some firms may play reputational games and only symbolically maintain sustainable practices, while others value the involvement of NGOs and seek to incorporate their feedback and suggestions to a large extent. The research contained in this issue shows that substantive engagement does take place in response to stakeholder engagement. However, even when firms are innovative and have slack resources, different firms still pursue different strategies and several open questions for future research remain.

\section{Special Issue Papers}

In the first paper of this special issue, Perez-Batres et al. (2012) examine the question of what determines a firm's strategic choice toward more symbolic or substantive CSR action. They empirically investigate two voluntary selfregulatory codes: the United Nations Global Compact and the Global Reporting Initiative. Their results contribute to the literature on self-regulatory programs in four important ways. First, the empirical results show that not all stakeholders are equally relevant when firms decide to engage in self-regulatory codes. Instead, it is important to consider the salience of individual stakeholder groups. Second, the authors show that high stakeholder scrutiny has a positive effect on firm decisions to engage substantively, not only symbolically. Substantive involvement reflects true commitment to sustainability whereas symbolic engagement means actions are decoupled from actual implementation. Third, the authors conclude that there is a positive association between resource discretion and both symbolic and substantive actions. Thus, even though a firm has slack 
resources, it still may consider the symbolic option. Fourth, the results suggest that firms from perceived "dirtier" industries are more likely to join substantive self-regulatory codes than firms from perceived "cleaner" industries. With these results, the paper provides a deeper context for understanding how stakeholder groups, pollution levels, and slack resources influence organizations' decisions around CSR compliance and draws important conclusions for future studies on corporate greenwashing.

Perego and Kolk's (2012) contribution to this issue focuses on the evolution of third-party assurance of sustainability reports of multinational corporations. The authors examine a panel of Fortune Global 250 firms over a period of 10 years and investigate how evolving auditing practices shape the quality of sustainability assurance statements. The study contributes to the literature on international accountability standards for sustainability in several ways. The results illustrate great variability in the adoption pattern of assurance practices and adherence to related standards. Based on the analysis, the authors emphasize the relevance of external institutional pressures as well as internal resources and capabilities as underlying factors driving the adoption of assurance. Several firms seem to project a decoupled or symbolic image of accountability through assurance, thereby undermining the credibility of these verification practices. In practical terms, the authors document that while the percentage of verified reports increased over the time frame, the diffusion of sustainability assurance remains limited. Based on these insights, the authors discuss avenues for future studies in investigating the role of sustainability assurance for sustaining sustainability in organizations.

Thomas and Lamm (2012) address the question of how a firm can be successful at integrating sustainability concerns into strategic and operational decision-making processes while still meeting its traditional business goals. They elaborate on a conceptual model based on Ajzen's Theory of Planned Behavior $(1985,1991)$ that operates at the individual managerial level. Their conceptual model indicates that the perceived legitimacy of sustainability, as applied to firms, can affect managers' intentions to incorporate sustainability into decision-making processes. The contributions of this study are deep and diverse. Mainly, Thomas and Lamm develop a legitimacy framework to enhance understanding of the attitudinal basis of legitimacy. The elements of the framework may also enrich Ajzen's Theory of Planned Behavior. The theory of planned behavior describes how attitudes, subjective norms, and perceived behavioral control affect intention and/or behavior (Ajzen 1991). Attitudes are the personal positive or negative valuation of a behavior and norms reflect perceived social pressure to engage in or avoid behavior. Thomas and Lamm identified six elemental attitudes of legitimacy that can be aggregated to yield a meta-attitude in regards to the legitimacy of sustainability. If these six elements are to be incorporated into Ajzen's theory, three of the elements fall within the attitudes component and the other three falls within the norms component, thus providing a greater depth of understanding of the framework. Also, the authors illustrate the framework's practical implications by discussing its relevance for implementing and sustaining sustainability programs in organizations. Lastly, the authors emphasize the need for future research that tests this model that seeks to explain: (1) how attitudes toward various aspects of sustainability affect its legitimacy, and (2) how the perceived legitimacy of sustainability affects the behavior of organizational actors who can either impede or facilitate the success of sustainability initiatives.

Chakrabarty and Wang (2012) empirically analyze particular factors that facilitate the initial development and the long-term sustenance of MNCs' sustainability practices. Specifically, their results show that R\&D and internationalization, in synergy, enable MNCs to develop more sustainable practices and maintain them in the long run. Their research contributes to prior literature on MNCs and sustainability in three ways. First, previous research has analyzed how MNCs initiate the development of sustainability practices (Delgado-Ceballos et al. 2011; de Lange 2010). The authors extend this work by exploring the factors influencing the long-term sustenance of sustainability practices. Second, previous studies have paid attention to the independent effects of $R \& D$ and internationalization on sustainability practices (Hart 1997; Wagner 2007). In contrast, this study examines the joint effects of these two variables and finds that, together, they have a positive effect on both the initial development and the long-term sustenance of sustainability practices. Finally, the authors modify the view that MNCs should mainly focus on core profit-generating strategies, and should therefore, not be distracted by other matters such as sustainability. The authors' findings reveal that the capabilities to both develop and maintain sustainability practices can arise from the synergies between two core strategies$\mathrm{R} \& \mathrm{D}$ and internationalization. An MNC that simultaneously pursues both $R \& D$ and internationalization would be in a better position to deliver on sustainability goals. Thus, the authors argue that it would be misleading to view core profit-generating strategies as being incompatible with sustainability goals. It would risk overlooking important capabilities that enable MNCs to have a positive impact on society and environment.

Lin's (2012) empirical study examines the antecedents of firms' decisions to develop cross-industry and -sector partnerships, rather than same industry inter-firm alliances, to advance proactive environmental strategies. Her main 
contribution is to examine cross-sector partnerships, not having had much previous study (Rondinelli and London 2003). For example, firms may partner with government, non-governmental organizations, universities, and firms in other industries. Thus, in her study, the focal firms are already concerned with sustainable practices and seek to further them through learning alliances. What are the characteristics of these firms that engage in cross-sector partnerships? The theoretical lens of the study is the resource-based view. It considers alliance partner heterogeneity in terms of the breadth or diversity of complementary capabilities of the organizations that engage with each other. The various types of organizational partners differ in their competencies so as to pool diverse knowledge that, in turn, can spawn innovation (Kotabe and Swan 1995; Powell et al. 1996; Sakakibara 1997). Based on a set of 146 firms' participation in US-based environmental alliances for the period 1991-2007, Lin (2012) finds that firms with an innovative orientation or more years of alliance experience tend to choose cross-sector partners. Also, firms that do ally with cross-sector partners tend to engage in proactive environmental strategies. The author's measure of the dependent variable, engagement in proactive environmental strategies, is an index with four levels of environmental strategies. This is an additional contribution to the literature. The first level of the index, pollution control, is reactive whereas pollution prevention, product stewardship, and sustainable development are three increasingly higher levels of proactivity. A very interesting aspect of her results is that, contrary to previous research, she does not find that cross-industry partnerships lead to proactive environmental strategies. This emphasizes the unique and valuable roles that other types of organizations have in influencing firms. Future research could examine the patterns found in a more international context since the sample is US-based.

In the last paper, Caprar and Neville (2012) propose a theoretical model that draws from both the national culture and institutional theory literatures so as to explicate the role of national culture as a context for the institutional pressures that drive sustainability adoption in firms. By exploring how the two literatures can inform each other, they build on an interesting tension such that the two areas seem to compete for the same intellectual space (Morrill 2012). Their model draws upon institutional theorists' distinction between the existence of institutional pressures and actors' agency when responding to these pressures. They argue that these processes are separately embedded in national culture. Also, they apply their model to questions arising in the sustainability literature to illustrate the model's usefulness. For example, the authors explain that the effect of institutional pressures on firms to be sustainable is limited since there is wide variability in conformance to sustainable practices. Instead, national culture can help to explain the variability in adoption. What they refer to as a "norming" effect occurs when national culture influences the development of legitimation pressures. The national context encompasses norms and values that are compatible with the principles of sustainability such that sustainability-relevant institutions arise. This, in turn, increases the likelihood of sustainability adoption. The institutional pressures may occur at local, national and international levels, in global institutions, for example. These "norming" pressures increase the likelihood of sustainability adoption, but are also dependent on a "conforming" effect that is also affected by national culture. The authors theorize that firms in tight national cultures, those with clear and strongly sanctioned norms, will more likely adopt sustainable activity than firms in loose cultures, those that have less pervasive norms and are more tolerant of deviance. These separate norming and conforming effects occur in recognition of the fact that firms may value sustainability (norming), but may not necessarily act in accordance with its principles (conforming).

\section{Final Thoughts}

Sustaining sustainability in organizations: Are we on track yet? Do we need more progress? One may argue that some firms seem to be on track. At least there are many outstanding examples of how firms and managers follow a best-practice approach. But looking at the big picture, it becomes more than obvious that we need additional urgent and far-reaching action. In 2007, humanity used the equivalent of 1.5 planets; by 2030 it is projected that we will require the capacity of two Earths (WWF, Zoological Society of London \& Global Footprint Network 2010). Despite the financial crisis, global $\mathrm{CO}_{2}$ emissions increased by $4.4 \%$ between 2008 and 2010 (from 29.3 to 30.6 GT). These alarming trends illustrate one key challenge society faces: on an aggregate level, current production and consumption practices are, by far, not sustainable. Reflecting on this challenge, the intention of this special issue is to provide greater insight into how organizations are managing sustainability so that the practices are maintained and enhanced. We hope that this issue has begun to fulfill this ambitious mission that will spawn further related research so that scholars and practitioners will keep sustainability at the forefront of strategy and operations.

In fact, we believe that the six papers in this issue are very fruitful for future research. Some of the key ideas are outlined here so as to consolidate them in brief. First, greenwashing is a critical concept that needs greater understanding (Perez-Batres et al. (2012)). A theme running through this issue is the perception that firms either 
symbolically or substantially adopt and maintain sustainable practices. In other terms, they may value sustainability (norming), but not enact it (conforming) (Caprar and Neville 2012). However, is it possible that symbolic adoption represents, in some cases at least, first steps toward substantive adoption (Perez-Batres et al. 2012). Also, how do stakeholders hinder firms' continuance of sustainability and what responsibilities do external stakeholders have for encouraging firms' compliance and improvement? Thomas and Lamm (2012) suggest that managers' attitudes are consequential and perhaps, external attitudes are also. Future research could empirically investigate how internal and external attitudes about the legitimacy of sustainability affect its continuance in firms; a challenge will be how to measure attitudes (Thomas and Lamm 2012). Alongside these issues is the politics of sustainability and the requirement for further understanding of how, when there is such a diversity of standards, firms choose with which one(s) they will comply (Perego and Kolk 2012).

Another critical issue that will drive future research is the opportunity or requirement to combine current theories. In past work, similar phenomena have been investigated in different disciplines and research streams. Thus, separate results are reported within the research domains. This prevents cross-cutting research insights and advances toward far-reaching answers to pressing issues. Especially in light of important, global challenges society is facing due to unsustainable production and consumption patterns, combining insights from different theoretical thinking may facilitate finding urgently required answers. For example, Perego and Kolk (2012) suggest that a cross-disciplinary approach, incorporating accounting and audit literature into strategy and organizations research would offer deeper insights into the determinants of voluntary corporate financial disclosure. Also, Caprar and Neville (2012) remark on the need to encourage constructive dialogue among disciplines that are concerned with similar questions so as to improve overall understanding of research phenomena.

Also, to build on the international perspective in future research, many suggestions are offered. Perego and Kolk (2012) suggest that the joint examination of country and firm-level factors as drivers of sustainability assurance could be fruitful, especially with the growing importance of international accounting standards. Moreover, open questions remain regarding the emergence, relevance, and interplay of potential factors affecting multinationals' behavior, both internal and external to the MNC. In addition to those studied already, interesting factors could be: ownership structure, organizational culture, industry structure, and institutional pressures (Chakrabarty and Wang 2012; Lin 2012; Caprar and Neville 2012). Understanding the effects of different sources of institutional pressures and their interactions that could play out in MNCs are of interest (Caprar and Neville 2012). Also, further investigating the effects of cross-sector partnerships more internationally and the differentiated role national culture may play locally, nationally, or globally could be fruitful (Lin 2012; Caprar and Neville 2012).

Finally, many papers investigated the role of stakeholders and firms' disclosure practices for sustaining sustainability in organizations. In this context, we see financial institutions, e.g., banks, insurance companies, and institutional and private investors, as key players that have received less recognition in research. Albeit sustainable investment practices have increasingly gained importance in capital markets (Bauer et al. 2005; Galema et al. 2008), as of date, financial stakeholders do not play an important and far-reaching role in fostering sustainable business practices. Many areas for future research remain. For example, the effectiveness of contemporary sustainable investment practices in terms of their actual contribution to sustainable development needs investigation. Also, how can different (economic, sociological, psychological, etc.) theories of equity market participants' decision making and business cycles help in the understanding of the barriers and motivations for sustainable investments? What are the characteristics of financial stakeholders who promote sustainability compared to those of conventional investors? This list is only a small sampling of what the area of sustainable finance suggests for future research. Given all the future research implied by this topic area as well as all of those aforementioned, we expect that the work represented in this issue will stimulate thought in many scholars' minds so that future research programs stemming from this issue will be prolific.

\section{References}

Ajzen, I. (1985). From intentions to actions: A theory of planned behavior. In J. Kuhl \& J. Beckmann (Eds.), Action control: From cognition to behavior (pp. 11-39). New York: Springer.

Ajzen, I. (1991). The theory of planned behaviour. Organizational Behavior and Human Decision Processes, 50, 179-211.

Aragón-Correa, J. A., \& Sharma, S. (2003). A contingent resourcebased view of proactive corporate environmental strategy. Academy of Management Review, 28(1), 71-88.

Bansal, P. (2005). Evolving sustainably: A longitudinal study of corporate sustainable development. Strategic Management Journal, 26(3), 197-218.

Barney, J. (1991). Firm resources and sustained competitive advantage. Journal of Management, 17(1), 99-120.

Bauer, R., Koedijk, K., \& Otten, R. (2005). International evidence on ethical mutual fund performance and investment style. Journal of Banking \& Finance, 29(7), 1751-1767.

Caprar, D., \& Neville, B. (2012) "Norming and conforming": Integrating cultural and institutional explanations for sustainability adoption in business', Journal of Business Ethics. doi: 10.1007/s10551-012-1424-1 
Chakrabarty, S., \& Wang, L. (2012). The long-term sustenance of sustainability practices in MNCs: A dynamic capabilities perspective of the role of R\&D and internationalization. Journal of Business Ethics. doi:10.1007/s10551-012-1422-3

Chatterji, A. K., \& Listokin, S. (2007). Corporate social irresponsibility. Democracy: A Journal of Ideas, 3, 52-63.

de Lange, D. E. (2010). Research companion to green international management: A guide for future research, collaboration and review writing. Northampton: Edward Elgar.

Delgado-Ceballos, J., Aragón-Correa, J. A., Ortiz-de-Mandojana, N., \& Rueda-Manzanares, A. (2011). The effect of internal barriers on the connection between stakeholder integration and proactive environmental strategies. Journal of Business Ethics, 107(3), 281-293.

Delmas, M. A., \& Cuerel Burbano, V. (2011). Environmental management and regulatory uncertainty. California Management Review, 54(1), 64-87.

Elkington, J. (1998). Cannibals with forks: the triple bottom line of 21 st century business. Oxford: Capstone.

Galema, R., Plantinga, A., \& Scholtens, B. (2008). The stocks at stake: Return and risk in socially responsible investment. Journal of Banking \& Finance, 32(12), 2646-2654.

Gladwin, T., Kennelly, J. J., \& Krause, T. (1995). Shifting paradigms for sustainable development: implications for management theory and research. Academy of Management Review, 20, 874-907.

GRI. (2011). A new phase: The growth of sustainability reporting. GRI's Year in review 2010/11. Amsterdam: Global Reporting Initiative.

Hart, S. (1995). A natural-resource-based view of the firm. Academy of Management Review, 20(4), 986-1014.

Hart, S. L. (1997). Beyond greening: Strategies for a sustainable world. Harvard Business Review, 75(1), 66-76.

Hess, D. (2008). The three pillars of corporate social reporting as new governance regulation: Disclosure, dialogue and development. Business Ethics Quarterly, 18(4), 447-482.

Hoffman, A. J. (1999). Institutional evolution and change: Environmentalism and the US chemical industry. Academy of Management Journal, 42(4), 351-371.

Husted, B. W., \& Allen, D. B. (2007). Corporate social strategy in multinational enterprises: Antecedents and value creation. Journal of Business Ethics, 74(4), 345-361.

Kassinis, G., \& Vafeas, N. (2006). Stakeholder pressures and environmental performance. Academy of Management Journal, 49(1), 145-159.

Kotabe, M., \& Swan, K. S. (1995). The role of strategic alliances in high-technology new product development. Strategic Management Journal, 16(8), 621-636.
Lin, H. (2012). Cross-sector alliances for corporate social responsibility partner heterogeneity moderates environmental strategy outcomes. Journal of Business Ethics. doi:10.1007/s10551-012$1423-2$

Luo, Y. (2000). Dynamic capabilities in international expansion. Journal of World Business, 35(4), 355-378.

Morrill, C. (2012). From bridges to trading zones in organizational culture and institutional research. Journal of Management Inquiry, 21(1), 109-113.

Perego, P., \& Kolk, A. (2012). Multinationals' accountability on sustainability: The evolution of third-party assurance of sustainability reports. Journal of Business Ethics. doi:10.1007/s10551012-1420-5

Perez-Batres, L. A., Doh, J. P., Miller V. V., \& Pisani, M. J. (2012). Stakeholder pressures as determinants of CSR strategic choice: Why do firms chose symbolic versus substantive self-regulatory codes of conduct? Journal of Business Ethics. doi:10.1007/s10551012-1419-y

Powell, W. W., Koput, K. W., \& Smith-Doerr, L. (1996). Interorganizational collaborations and the locus of innovation: Networks of learning in biotechnology. Administrative Science Quarterly, $41,116-145$.

Rondinelli, D. A., \& London, T. (2003). How corporations and environmental groups cooperate: Assessing cross-sector alliances and collaborations. Academy of Management Executive, 17(1), 61-76.

Sakakibara, M. (1997). Heterogeneity of firm capabilities and cooperative research and development: An empirical examination of motives. Strategic Management Journal, 18, 143-164.

Teece, D. J., Pisano, G., \& Shuen, A. (1997). Dynamic capabilities and strategic management. Strategic Management Journal, 18(7), 509-533.

Thomas, T. E., \& Lamm, E. (2012). Legitimacy and organizational sustainability. Journal of Business Ethics. doi:10.1007/s10551012-1421-4

Wagner, M. (2007). On the relationship between environmental management, environmental innovation and patenting: Evidence from German manufacturing firms. Research Policy, 36(10), $1587-1602$.

World Commission on Environment and Development. (1987). Our common future. Oxford: Oxford University Press.

WWF, Zoological Society of London, \& Global Footprint Network. (2010). Living planet report 2010: Biodiversity, biocapacity and development. Gland, London: Worldwide Fund For Nature. 